\title{
PORTABLE IMAGERY QUALITY ASSESSMENT TEST FIELD FOR UAV SENSORS
}

\author{
R. Dąbrowski ${ }^{\text {a }}$, A. Jenerowicz ${ }^{\text {a* }}$ \\ ${ }^{a}$ Military University of Technology, Faculty of Civil Engineering and Geodesy, Institute of Geodesy, Department of Remote \\ Sensing and Photogrammetry, gen. S. Kaliskiego 2 st., 00-908 Warsaw, Poland - (rafal.dabrowski, \\ agnieszka.jenerowicz)@wat.edu.pl
}

KEY WORDS: UAV, image quality, quality assessment, portable test field, sensor resolution, remote sensing

\begin{abstract}
:
Nowadays the imagery data acquired from UAV sensors are the main source of all data used in various remote sensing applications, photogrammetry projects and in imagery intelligence (IMINT) as well as in other tasks as decision support. Therefore quality assessment of such imagery is an important task. The research team from Military University of Technology, Faculty of Civil Engineering and Geodesy, Geodesy Institute, Department of Remote Sensing and Photogrammetry has designed and prepared special test field- The Portable Imagery Quality Assessment Test Field (PIQuAT) that provides quality assessment in field conditions of images obtained with sensors mounted on UAVs. The PIQuAT consists of 6 individual segments, when combined allow for determine radiometric, spectral and spatial resolution of images acquired from UAVs. All segments of the PIQuAT can be used together in various configurations or independently. All elements of The Portable Imagery Quality Assessment Test Field were tested in laboratory conditions in terms of their radiometry and spectral reflectance characteristics.
\end{abstract}

\section{INTRODUCTION}

Nowadays there is a great increase in the demand for geospatial information- especially remote sensing data that were obtained in different ranges of the electromagnetic spectrum with different kind of sensors (e.g. multispectral, hyperspectral, etc.), both for military and civilian applications. Hugh amount of remote sensing data, especially the imagery data, that are acquired all over the world, at different heights (i.e. from the ground, from the satellites, aircraft or unmanned airborne platforms) and in different ranges of the electromagnetic spectrum with different types of sensor (i.e. passive and active), are reliable material to carry on various types of spatial and spectral analyses.

In the last few years it can be observed a significant increase in the availability of different imagery data, especially that obtained with relatively economic and optimum sensors, that are placed on Unmanned Aerial Vehicles (UAV), which can be used both for photogrammetry and remote sensing (Colomina \& Molina, 2014; Dąbrowski et al., 2014). Unmanned Aerial Vehicles have a great potential for various remote sensing applications which is caused by several advantages of UAVs over satellites and aircraft. The most important advantage of UAVs is the possibility of their quick and repeatedly deployment. Moreover they are less costly and much more safer than standard aircraft. UAVs can fly at various heights and are flexible in the terms of mission planning. In addition to that it is possible to obtain imagery at sub-decimetre resolution with sensors that are mounted on them (spatial resolution of sensors mounted on UAVs is greater than satellite sensors, i.e. several centimetres instead of hundreds of meters) and unlike the satellite and aerial observations they do not have observation gaps due to high cloud coverage or other atmospheric phenomena and their coverage is not limited over certain regions due to orbit around the Earth (Hein \& Bento, 2008; Bending et al., 2012).
The increased availability of UAVs in the recent years and all mentioned advantages of unnamed aerial systems have resulted in their frequent adoption for a growing range of different remote sensing tasks (environmental and anthropogenic) (Gupta et al., 2013) which among others include fine- scale topographic mapping, homeland security (Henriques, 2014), urban mapping and monitoring (Fernandez Galarreta et al., 2015), vegetation mapping (Berni et al., 2009; Salami et al., 2014; von Bueren et al., 2015, Feng et al., 2015), precision agriculture (Honkavaara et al., 2013), wetlands monitoring, wildfire research (i.e. forest fire monitoring) (Casbeer et al., 2005; Ollero et al., 2006; Merino \& Ollero, 2010), river detection and tracking, disaster management and surveillance for emergency disasters (Ezequiel et al., 2014). Furthermore UAVs are used for Earth science research, humanitarian observations, traffic monitoring, inspection of industrial facilities like gas pipeline monitoring, volcanic gas sampling and many other environmental tasks (e.g. aquatic ecosystem monitoring (Flynn \& Chapra, 2014), and coastal management (Mancini et al., 2013), ice cover monitoring (Lešinskis et al., 2012), monitoring of wildlife (Jones IV et al., 2006), monitoring of climate change and observing the weather phenomena, etc.) and digital elevation model of terrain (Dowling \& Gallant, 2013; Ruiz et al., 2013).

The implementation of all mentioned applications with the use of UAVs is possible with the use of various sensors working in different range electromagnetic spectrum range, that can be mounted on unmanned aerial vehicles. Nowadays, depending on the application it is possible to use a RGB-IR digital cameras, video cameras, multispectral and hyperspectral sensors, thermal cameras or even a LIDAR sensor.

The imagery data acquired with UAV sensors are the main source of all data used in various remote sensing applications, photogrammetry projects and in an imagery intelligence (IMINT). In case of imaging sensors mounted on different kinds of UAVs, the determination of an interpretational potential of acquired imagery is one of the most important thing in the chain 
of data acquisition, data post- processing and image analysis for remote sensing and photogrammetric purposes. Field- testing and calibration of digital imagery sensors mounted on UAVs are essential to assess their quality and characterize their performance, therefore spatial, radiometric and spectral properties of digital imagery systems not only require calibration but also testing before the operational use.

UAVs' sensors can be and are tested in the laboratory conditions, but due to various flight parameters of UAVs, exposition parameters of imaging sensor, light conditions and many others that can occur during the UAV flight it is important to maintain control over spectral, radiometric and spatial parameters of used sensor. Due to changing external conditions it is important to assess the image quality and test the imaging system in terms of radiometry, spectral and spatial parameters in field conditions before operational flight. To provide such assessment it is important to have field test, that would be portable and applicable for imaging sensors in many field conditions.

\section{IMAGE QUALITY ASSESSMENT}

Digital images obtained with sensors mounted on UAVs are subject to a variety distortions during acquisitions, like external conditions (e.g. amount of light, exposure time, wind speed, etc.). Therefore the assessment of their quality is very important. Till now the only method of quantifying visual image quality was through subjective evaluation (Zhou et al., 2004). Image quality can be defined as subjective impression ranging from poor to excellent. In practice, however, only subjective evaluation was usually too inconvenient, timeconsuming and expensive, especially for multispectral and hyperspectral images.

Humans perception of good image quality assessment is based on the real- world experiences of seeing colours, intensities, textures and distinguishing different objects. Image quality is a subjective impression ranging from poor to excellent- that is a somewhat learned ability, accomplished by the brain. Therefore perceptual quality of the same scene can vary between individuals and temporally for the same individual. Because of large variations exist in an observer's judgment as to the correct rank ordering of image quality from poor to best, it is impossible to place image quality on an absolute scale (Holst, 1998).

There are many formulas for assess image quality. One of the possibility to evaluate the quality of image quality is evaluation its spectral, radiometric and spatial resolution.

There are many tests that provide the assessment of image quality of aerial sensors in the field conditions. However due to their dimensions and construction they are permanent field test, that cannot be used for evaluation of quality of images obtained with sensors mounted on UAVs. All such test provide the possibility of checking image quality in terms of spectral, spatial and radiometric resolution. Usually they consist of Siemens star and/ or sparse resolution bar target, greyscale, and different reflectance targets. e.g. Honkavaara et al. (2006), Honkavaara et al. (2008), Honkavaara et al. (2010), Markelin et al. (2010).

In response to lack of the portable test field for the image quality assessment of sensors mounted on UAVs, that could be used in different conditions and for gran variety of sensors, the research team from Military University of Technology, Faculty of Civil Engineering and Geodesy, Geodesy Institute, Department of Remote Sensing and Photogrammetry has designed and prepared special test field- The Portable Imagery Quality Assessment Test Field (PIQuAT), that will fulfil the gap in this area. The PIQuAT (The Portable Imagery Quality Assessment Test Field) is the portable test field, dedicated for different sensors mounted on UAVs that allows for evaluation of the quality of images. The PIQuAT, designed and build by research team from MUT allow for determine radiometric, spectral and spatial resolution of images acquired from UAVs.

\section{THE PIQUAT}

The Portable Imagery Quality Assessment Test Field (PIQuAT) is the portable test field, dedicated for different sensors mounted on UAVs that allows for evaluation of the quality of images. It consists of 6 individual parts made from wooden plates, $70 \times 70 \mathrm{~cm}$ each, when combined allow for determine radiometric, spectral and spatial resolution of images acquired from UAVs. All parts of the PIQuAT were checked in the laboratory conditions. All segments of the PIQuAT can be used together in various configurations or independently.

\subsection{Spatial resolution}

The spatial resolution describes the ability of a sensor to identify the smallest size detail of a pattern on an image. It is the distance between distinguishable patterns or objects in an image that can be separated from each other and is often expressed in meters. Spatial resolution of digital sensors depends primarily on their Instantaneous Field of View (IFOV) and the flight height (Levin, 1999). Spatial resolution and spatial attributes of sensor can be described with GRD (Ground Resolved Distance) and GSD (Ground Sampling Distance).

To determine spatial resolution for UAVs' sensors there is the first segment of the PIQuAT. It consists of a quarter of the 32 sectorial Siemens star (radius- $70 \mathrm{~cm}$ )- Figure 1, Figure 2, that allows to determine the spatial resolution of the sensor.

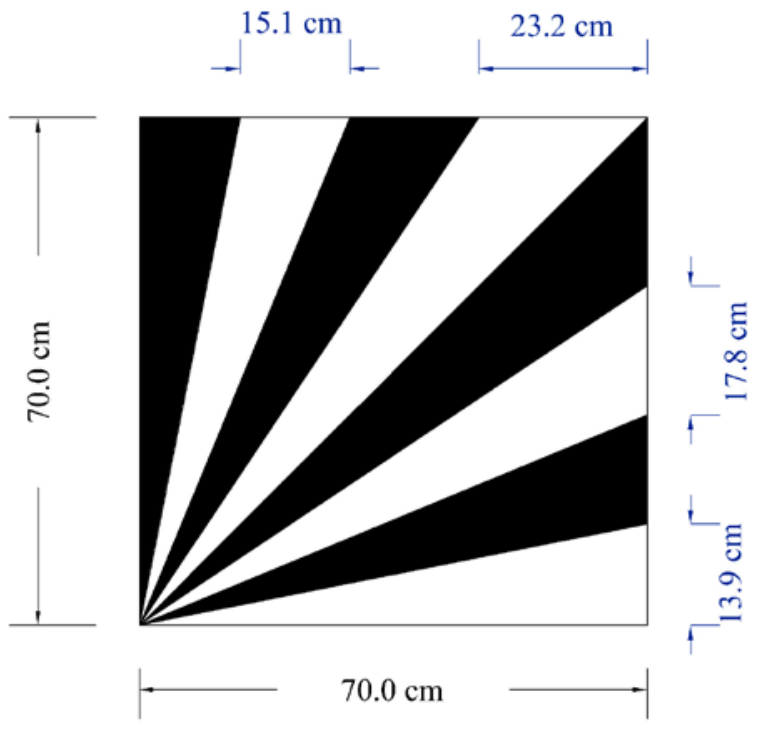

Figure 1. The project of the segment no 1: the quarter of Siemens star (diameter $70 \mathrm{~cm}$ ) 


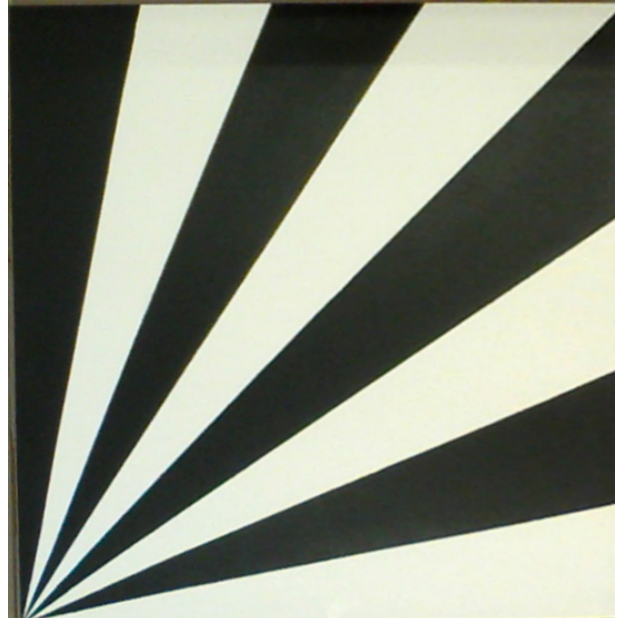

Figure 2. Segment no 1: the quarter of Siemens star (image obtained with RGB camera)

\subsection{Radiometric resolution}

The radiometric characteristics describe the actual information content of an image. Every time an image is acquired on film or by a detector, its sensitivity to the magnitude of the electromagnetic energy determines the radiometric resolution. The radiometric resolution can be defined as the sensitivity of a sensor to incoming flux (Levin, 1999; Orych et al., 2014).

The second segment if the PIQuAT is built from three parts, that together form a 12- level greyscale board (from black- 3\% reflectance to white- $85 \%$ reflectance). This segment should be used for the evaluation of radiometric resolution- Figure 3 . Thanks to 12- levels of grey it is possible to check the radiometric capacity of sensor's array.

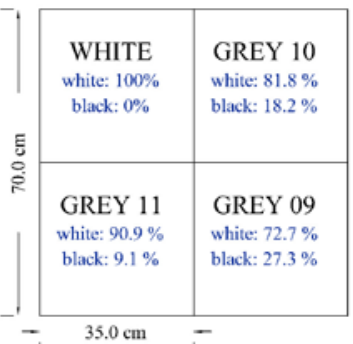

\begin{tabular}{|c|c|}
\hline $\begin{array}{c}\text { GREY 08 } \\
\text { white: } 63.6 \% \\
\text { black: } 36.4 \%\end{array}$ & $\begin{array}{c}\text { GREY 06 } \\
\text { white: } 45.5 \% \\
\text { black: } 54.5 \%\end{array}$ \\
\hline $\begin{array}{c}\text { GREY 07 } \\
\text { white: } 54.5 \% \\
\text { black: } 45.5 \%\end{array}$ & $\begin{array}{c}\text { GREY 05 } \\
\text { white: } 36.4 \% \\
\text { black: } 63.6 \%\end{array}$ \\
\hline
\end{tabular}

\begin{tabular}{|c|c|}
\hline $\begin{array}{c}\text { GREY 04 } \\
\text { white: } 27.3 \% \\
\text { black: } 72.7 \%\end{array}$ & $\begin{array}{c}\text { GREY 02 } \\
\text { white: } 90.9 \% \\
\text { black: } 9.1 \%\end{array}$ \\
\hline $\begin{array}{c}\text { GREY 03 } \\
\text { white: } 18.2 \% \\
\text { black: } 81.8 \%\end{array}$ & $\begin{array}{c}\text { BLACK } \\
\text { white: } 0 \% \\
\text { black: } 100 \%\end{array}$ \\
\hline
\end{tabular}

Figure 3. The project of the segment no 2: 12- level grayscale
All shades of grey presented in the Figure 4 were prepared by mixing black and white paint in presented proportions (Figure 3). To avoid gloss only matt paint was used. Elements of the second segment (Figure 4) of the PIQuAT were measured in the laboratory conditions with the ASD FieldSpec 4 Wide-Res spectroradiometer. For all 12 elements, spectral reflectance coefficients were obtained, thereby this segment can also be used for assessment of spectral resolution of investigated sensor- Figure 5.

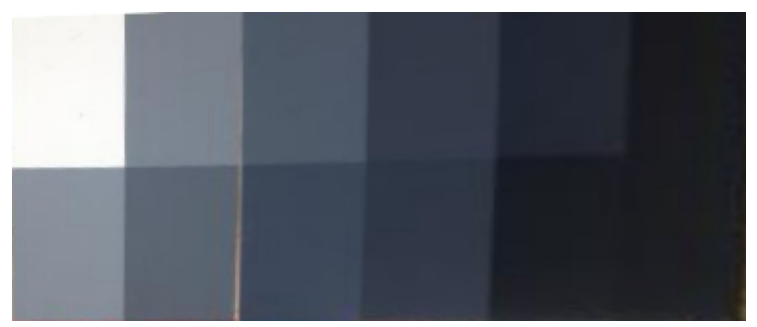

Figure 4. Segment no 2: 12- level greyscale (image obtained with RGB camera)

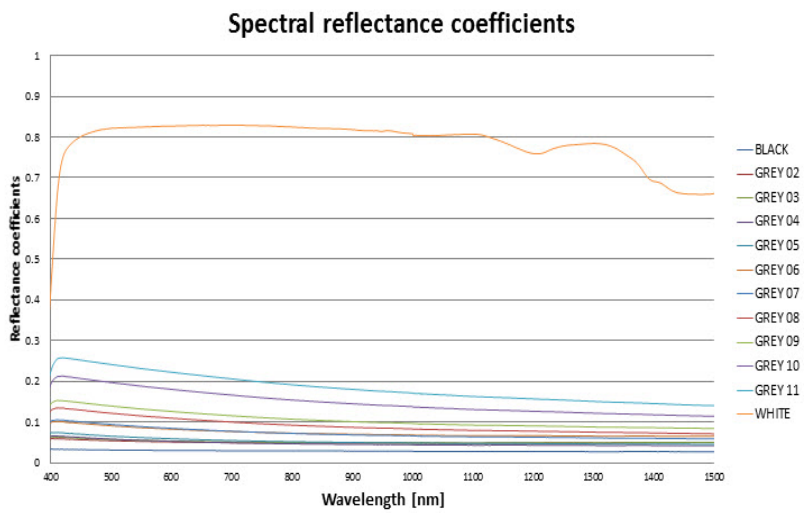

Figure 5. Segment no 2: Spectral reflectance coefficients of 12 elements

\subsection{Spectral resolution}

Spectral resolution is the sensitivity of a sensor to respond to a specific wavelength range. Different materials reflect and absorb differently at different wavelengths. The reflectance spectrum of a material is a plot of the fraction of radiation reflected as a function of the incident wavelength and serves as a unique signature for the material. In principle, a material can be identified from its spectral reflectance signature if the sensing system has sufficient spectral resolution to distinguish its spectrum from those of other materials (Levin, 1999). On the basis of this concept the las segment of the PIQuAT was designed. The third segment is built from two elements. First element is covered with four different types of materials- wood, red PVC, aluminium plate and green textile. Such diversity of materials will allow to evaluate the ability of sensor to distinguish different materials on the basis of their spectral reflectance coefficients- Figure 6- 7. 


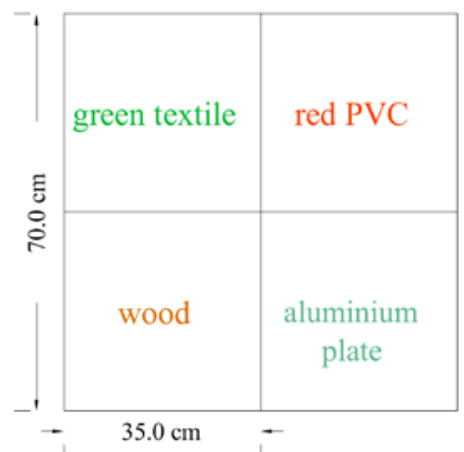

Figure 6. The project of the segment no 3: Various materials

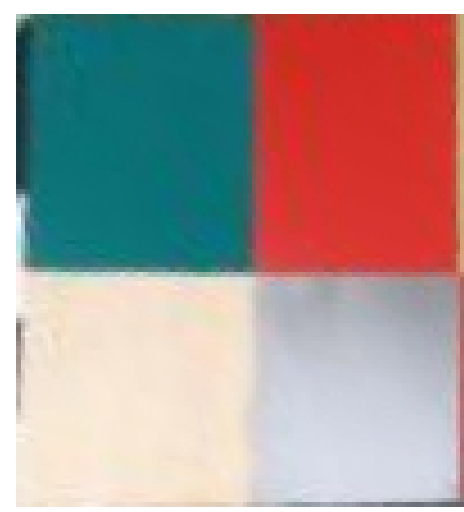

Figure 7. The segment no 3: Various materials (image obtained with RGB camera)

The second element used for assessment of spectral resolution is divided into four parts- two are painted with two different kinds of green paint and the next two with two kinds of red paint. Both red and green colours are almost indistinguishable with the naked eye or RGB sensor, but additional spectral channel, e.g. IR or narrower spectral channel, like in hyperspectral sensors would allow to distinguish different paints- Figure 8-9.

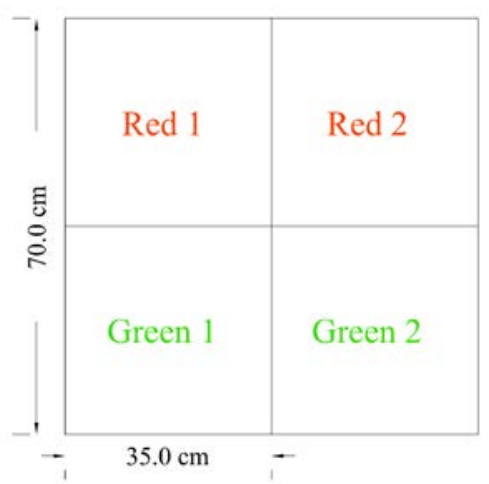

Figure 8. The project of the segment no 3: Different paint of the same colour

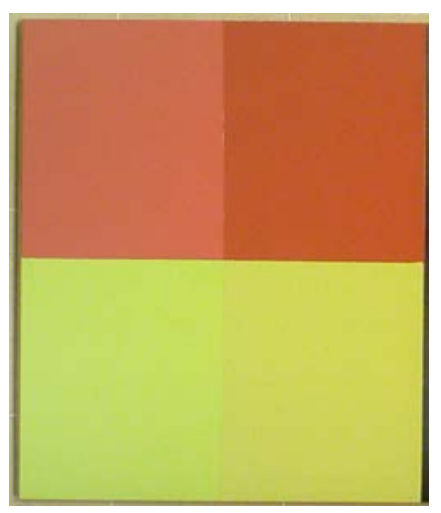

Figure 9. The segment no 3: Different paint of the same colour (image obtained with RGB camera)

For all element of this segment spectral reflectance coefficients were obtained in the laboratory conditions. As it is shown on the Figure 10, spectral characteristics of red colours as green are quite similar in the visible spectrum range, however it is possible to distinguish them in infrared spectral range.

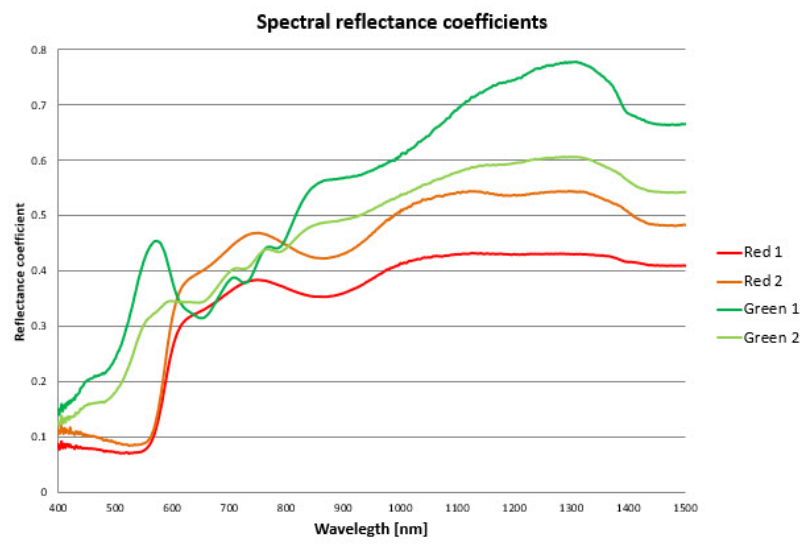

Figure 10. Segment no 3: Spectral reflectance coefficients of various paints

\section{PRELIMINARY RESULTS}

The application and the usefulness of the Portable Imagery Quality Assessment Test Field was tested with the camera Tetracam miniMCA in the field conditions. First results are presented on the Figures 11, 12 and 13- results discussion can be found in the article: Dabrowski et al. (2015) Preliminary results from the Portable Imagery Quality Assessment Test Field (PIQuAT) of UAV imagery for Imagery Reconnaissance Purposes. 


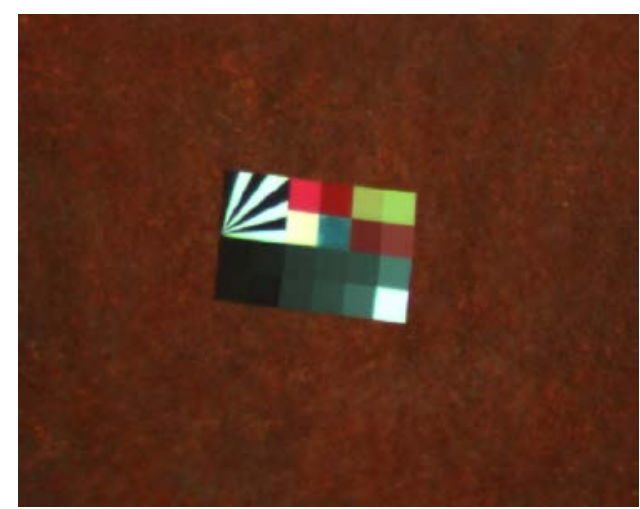

Figure 11. The PIQuAT- image obtained with miniMCA, (composition IR-G-B)

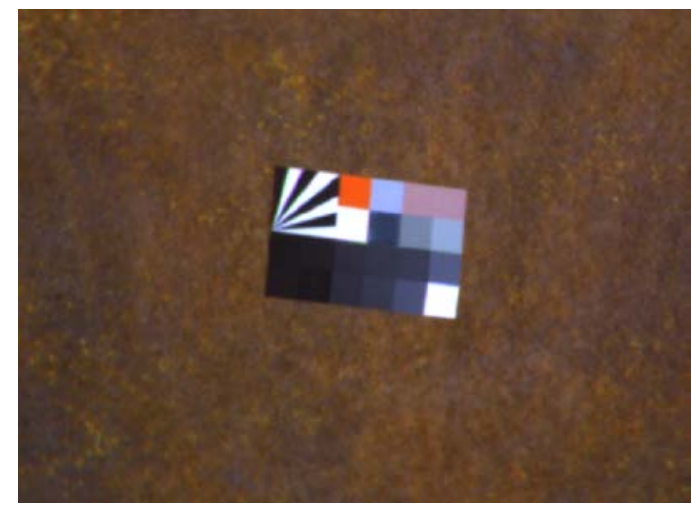

Figure 12. The PIQuAT- image obtained with miniMCA, (composition IR1-IR2-R)

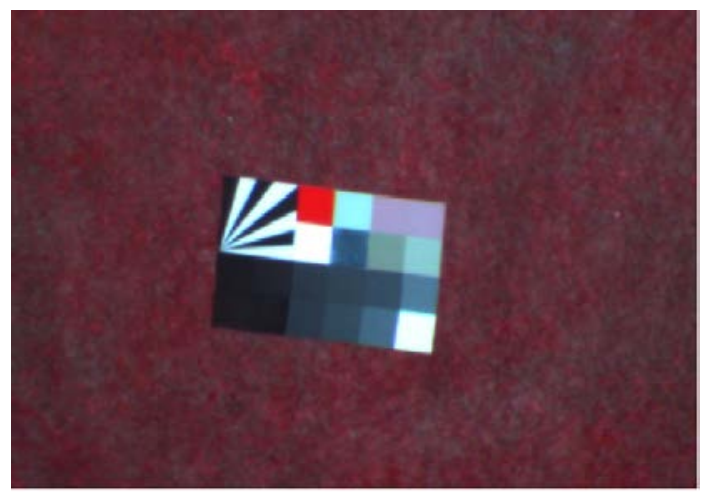

Figure 13. The PIQuAT- image obtained with miniMCA, (composition IR-R-G)

\section{CONCLUSIONS}

The Portable Imagery Quality Assessment Test Field (PIQuAT) that provides quality assessment in field conditions of images obtained with sensors mounted on UAVs. Thanks to its construction: separate segments, wooden plates and dimension (70 x $70 \mathrm{~cm}$ ), the PIQuAT can be transported with UAVs and mounted in any possible field conditions. All segments can be mounted separately or combined depending on the field conditions. Three segments that provide evaluation of three types of resolutions (i.e. spatial, spectral and radiometric) are ideal for image quality assessment. Moreover the portable construction of the PIQuAT allows using it without any durable interference with imaged area from UAV system. Therefore the PIQuAT facilitates testing different UAV sensors used for remote sensing or IMINT purposes in field conditions.

\section{ACKNOWLEDGEMENTS}

The presented article is part of research work carried out in the "Innovative remote sensing system for the monitoring of pollutants in rivers, offshore waters and flooded areas" projectPBS1/B9/8/2012 financed by the polish National Centre for Research and Development NCBiR.

\section{REFERENCES}

Bendig, J.; Bolten, A.; Bareth, G., 2012. Introducing a low-cost mini-UAV for thermal- and multispectral-imaging, International Archives of the Photogrammetry, Remote Sensing and Spatial Information Sciences Volume XXXIX-B1, in 2012 XXII ISPRS Congress, 25 August - 01 September 2012, Melbourne, Australia

Berni, J. A. J., Zarco-Tejada, P. J., Suárez, L. Fereres Castiel, E., 2009. Thermal and Narrow-band Multispectral Remote Sensing for Vegetation Monitoring from an Unmanned Aerial Vehicle. IEEE Transactions on Geoscience and Remote Sensing 47(3): 722-738 (2009)

von Bueren, S. K.; Burkart, A.; Hueni, A.; Rascher, U.; Tuohy, M. P.; Yule, I. J., 2015. Deploying four optical UAV-based sensors over grassland: challenges and limitations. Biogeosciences, Volume 12, Issue 1, 2015, pp.163-175

Casbeer, D.W., Beard, R.W., McLain, T.W., Sai-Ming Li, Mehra, R.K., 2005. Forest fire monitoring with multiple small UAVs. American Control Conference, 2005. Proceedings of the 2005. vol. 5 pp. 3530- 3535

Colomina, I., Molina, P., 2014. Unmanned aerial systems for photogrammetry and remote sensing: A review. ISPRS Journal of Photogrammetry and Remote Sensing 92 (2014), pp. 79-97

Dowling I, T., Gallant, J. C., 2013. High Resolution DEMs from Unmanned Aerial Vehicles. 20th International Congress on Modelling and Simulation, Adelaide, Australia, 1-6 December 2013, www.mssanz.org.au/modsim2013

Dąbrowski, R., Deliś, P., Wyszyński, M., 2014. Analysis of the possibility of using a video camera as a UAV sensor. The 9th International Conference "ENVIRONMENTAL ENGINEERING” 22-23 May 2014, Vilnius, Lithuania, eISSN 2029-7092 / eISBN 978-609-457-640-9

Ezequiel, C.A.F., Cua, M. ; Libatique, N.C. ; Tangonan, G.L. ; Alampay, R. ; Labuguen, R.T. ; Favila, C.M. ; Honrado, J.L.E. ; Canos, V. ; Devaney, C. ; Loreto, A.B. ; Bacusmo, J. ; Palma, B., 2014. UAV aerial imaging applications for post-disaster assessment, environmental management and infrastructure development. 2014 International Conference on Unmanned Aircraft Systems (ICUAS) 27- 30 May 2014, Orlando, FL, pp. 274- 283 
Feng, Q., Liu, J., Gong, J., 2015. UAV Remote Sensing for Urban Vegetation Mapping Using Random Forest and Texture Analysis. Remote Sens. 2015, 7, pp. 1074-1094

Fernandez Galarreta, J., Kerle, N., Gerke, M., 2015. UAVbased urban structural damage assessment using object-based image analysis and semantic reasoning. Nat. Hazards Earth Syst. Sci., 15, 2015, pp. 1087-1101

Flynn, K.F., Chapra, S.C., 2014. Remote Sensing of Submerged Aquatic Vegetation in a Shallow Non-Turbid River Using an Unmanned Aerial Vehicle. Remote Sens. 2014, 6, pp. 1281512836

Gupta, S. G., Ghonge, M. M., Jawandhiya, P. M., 2013. Review of Unmanned Aircraft System (UAS). IJARCET, Volume 2013; 2(4), pp. 1646-1658

Hein, G.; Bento, M. D. F., 2008. Unmanned Aerial Vehicles: An Overview, InsideGNSS 3(1), pp. 54-61

Henriques, J., 2014. Unmanned Aerial Vehicles (UAV): Drones for Military and Civilian Use. Global Research, March 21, 2014, http://www.globalresearch.ca/unmanned-aerial-vehiclesuav-drones-for-military-and-civilian-use/5374666

Holst, G. C., 1998. Sampling, Aliasing, and Data Fidelity for Electronic Imaging Systems, Communications, and Data Acquisition. J C D Pub (January 1998), Chapter 11

Honkavaara, E., Ahokas, E., Hyyppä, J., Jaakkola, J., Kaartinen, H., Kuittinen, R., Markelin, L., Nurminen, K., 2006. Geometric test field calibration of digital photogrammetric sensors. ISPRS Journal of Photogrammetry and Remote Sensing, Volume 60, Issue 6, September 2006, pp. 387-399

Honkavaara, E., Peltoniemi, J., Ahokas, E., Kuittinen, R., Hyyppä, R., Jaakkola, J., Kaartinen, H., Markelin, L., Nurminen, K., Suomalainen J., 2008. A permanent test field for digital photogrammetric systems. Photogrammetric Engineering \& Remote Sensing, volume 74, number 1, pp. 95-106

Honkavaara, E., Hakala, T., Peltoniemi, J., Suomalainen, J., Ahokas, E., Markelin, L., 2010. Analysis of Properties of Reflectance Reference Targets for Permanent Radiometric Test Sites of High Resolution Airborne Imaging Systems. Remote Sens. 2010, 2, pp. 1892-1917

Honkavaara, E., Saari, H., Kaivosoja, J., Pölönen, I., Hakala, T., Litkey, P., Mäkynen, J., Pesonen, L., 2013. Processing and Assessment of Spectrometric, Stereoscopic Imagery Collected Using a Lightweight UAV Spectral Camera for Precision Agriculture. Remote Sens. 2013, 5, pp. 5006-5039

Jones IV, G. P., Pearlstine, L. G., Percival, H. F., 2006. An Assessment of Small Unmanned Aerial Vehicles for Wildlife Research. Wildlife Society Bulletin, 34, pp. 750-758

Lešinskis, I., Urbahs, A., Pavlovičs, A., Petrovs, V., 2012. Monitoring of Ice Conditions at Sea Using Micro Class Unmanned Aerial Vehicles. Ūdens Transports un infrastruktūra: 14. starptautiskā konference, Latvia, Riga, 2627 April, 2012. Rìga: Latvijas Jūras Akadèmija, 2012, pp.57-63
Levin, N., 1999. 1 st Hydrographic Data Management course, IMO -International Maritime Academy, Trieste, Italy, "Fundamentals of remote sensing", http://geography.huji.ac.il/personal/Noam\%20Levin/1999fundamentals-of-remote-sensing.pdf (08 May. 2015)

Mancini, F., Dubbini, M., Gattelli, M., Stecchi, F., Fabbri, S., Gabbianelli, G., 2013. Using Unmanned Aerial Vehicles (UAV) for High-Resolution Reconstruction of Topography: The Structure from Motion Approach on Coastal Environments. Remote Sens. 2013, 5, pp. 6880-6898

Markelin, L., Honkavaara, E., Hakala, T., Suomalainen, J., Peltoniemi, J., 2010. Radiometric stability assessment of an airborne photogrammetric sensor in a test field ISPRS Journal of Photogrammetry and Remote Sensing 65: 4., pp. 409-421

Merino, L., Ollero, A., 2010. Automatic Forest Fire Monitoring and Measurement using Unmanned Aerial Vehicles. VI International Conference on Forest Fire Research D. X. Viegas (Ed.), 2010

Ollero, A., Martínez-de-Dios, J. R., Merino, L., 2006. Unmanned Aerial Vehicles as tools for forest-fire fighting, V International Conference on Forest Fire Research D. X. Viegas (Ed.), 2006

Orych, A., Walczykowski, P., Jenerowicz, A., Zdunek, Z., 2014. Impact of the cameras radiometric resolution on the accuracy of determining spectral reflectance coefficients. ISPRS - International Archives of the Photogrammetry, Remote Sensing and Spatial Information Sciences, Volume XL-1, 2014, pp.347-349

Rango, A., Laliberte, A., Herrick, J.E., Winters, C., Havstad, K.M., Steele, C., Browning, D.M., 2009. Unmanned aerial vehicle-based remote sensing for rangeland assessment, monitoring, and management. Journal of Applied Remote Sensing, Vol. 3, 033542, 13 August 2009

Ruiz, J. J., Diaz-Mas, L., Perez, F., Viguria, A., 2013. Evaluating the Accuracy of DEM Generation Algorithms from UAV Imagery. ISPRS - International Archives of the Photogrammetry, Remote Sensing and Spatial Information Sciences, Volume XL-1/W2, 2013, pp.333-337

Salamí, E., Barrado, C., Pastor, E., 2014. UAV Flight Experiments Applied to the Remote Sensing of Vegetated Areas. Remote Sens. 2014, 6, pp. 11051-11081

Zhou, W., Bovik, A.C., Sheikh, H.R., Simoncelli, E.P., 2004. Image quality assessment: from error visibility to structural similarity. IEEE Transactions on Image Processing, (Volume:13, Issue: 4 ), pp. 600- 612 